Warm up

\title{
Of UFOs and other thoughts
}

\section{P McCrory}

was recently whiling away a few joyful hours in transit in yet another anonymous airport on the way to another conference. After contemplating why in American airports it is physically impossible to get any sort of food that is capable of sustaining a healthy life, I felt the need to search for something to read. At a news stand, I found a copy of the Worst Case Survival Handbook (by Joshua Piven and David Borgenicht, Hardie Grant Books) to re-read. I was of course immediately taken by the instructions on how to foil an alien abduction. Some of you may think this is somewhat farfetched however I draw your attention to a recent survey that suggested 4 million Americans have been the victims of such events. Forearmed with that knowledge and with one eye looking for flying saucers, I was entranced.
The first reassuring suggestion in such situations was not to panic. I seem to recall the Hitchhiker's Guide To The Galaxy offers similar advice, and more importantly had it printed on its cover. Once calm, then attempt to control your thoughts. The extra terrestrial biological entity (or EBE to those in the know) may have the ability to read your mind. Mental pictures of anal probes should be avoided specifically. Once calm and clear, then resist verbally by firmly telling the EBE to leave you alone. Physical resistance should only be used as a last resort!

Although some of the chapters are more in a medical line (for example, how to treat a severed limb) and many useful phrases are helpfully included ("hello, I have been seriously wounded" and my favorite "you will never make me talk") I was struck by the absence of a sports medicine specific section. Perhaps we could have "how to have a urine drug test at the Olympics" or "what to do when the audiovisuals break down just before your conference presentation" or even "how to survive a sports medicine clinical exam". I can see a new book coming from those authors designed to fill this gap in our medical armamentarium.

Speaking of drug testing, I see that a recent poll in the Sunday Observer (21 April 2002) suggested that more than half of Britons aged between 18 and 24 have taken illegal drugs. In a time when decriminalisation of many "soft" drugs is being seriously considered, we have the hypocritical situation where our professional athletes are being increasingly tested for the same agents. Clearly many of these are not performance enhancing rather their effects are just the opposite!

How then do we balance our desire for "level playing field" where athletes are free of ergogenic agents? Given that we cannot even test for the newer anabolic hormonal derivatives, the enthusiasm by which athletes are tested for nonergogenic social drugs seems somewhat surprising. A little common sense would be helpful.

Beam me up, Scottie!

Br J Sports Med 2002;36:157 has been the subject of numerous studies. ${ }^{16-13}$

A commonly reported association of chronic brain injury in boxing is the presence on neuroimaging or post mortem studies of a cavum septum pellucidum. Some authors have suggested that a cavum represents an incidental anatomical variant of no clinical significance, ${ }^{14}$ whereas others have speculated that the higher incidence of cavum septum pellucidum in some studies represents an intrinsic predisposition to boxing in such people presumably on the basis of an abnormality in their limbic system. ${ }^{15}$ This paper sets out to examine the evidence for the significance of this anatomical variant in boxers. effects of boxing. Numerous accounts in both the medical literature and lay press have extensively documented the boxing deaths occurring in the ring since that time. $^{2}$

In 1928, Martland first described the syndrome of dementia pugilistica or chronic traumatic encephalopathy in boxers. ${ }^{3}$ Before this time, it was known in lay boxing circles that a few professional boxers developed the so called "punch

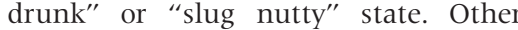
medical authors of the era further elucidated the clinical features of this condition. ${ }^{45}$ Since that time the association of chronic brain injury in boxers

\section{"A commonly reported association of chronic brain injury in boxing is the presence on neuroimaging of a cavum septum pellucidum"}

\section{ANATOMY}

The existence of cavum septi pellucidi has been known at least since the 15th century and the cavum vergae since the safer. ${ }^{1}$ These measures did not eliminate knockout in an attempt to make boxing 
Table 1 Incidence of cavum septi pellucidi (CSP) in various studies

\begin{tabular}{lll}
\hline Type of evidence & CSP incidence (\%) & Reference \\
\hline Neuropathology & 3 & 24 \\
& 20 & 20 \\
Neuroradiology & 60 & 25 \\
& 0.7 & 47 \\
1 & 49 \\
& 6 & 48 \\
9 & 52 \\
9 & 53 \\
10 & 38 \\
& 14 & 46 \\
17 & 37 \\
22 & 42 \\
37 & 36 \\
\hline
\end{tabular}

19th century ${ }^{16-18}$ In the modern era, the association of a cavum septum pellucidum and boxers was first incidentally noted by Spillane. ${ }^{19}$

The septum pellucidum rostrally forms the medial wall of the bodies of the lateral ventricles. The posterior margin is the fornix and the rostral and superior limits are formed by the corpus callosum. The septum consists of two leaves of glial tissue with both white and grey matter components, connected by the medial forebrain bundle to the hippocampus and through the fornix to the limbic system. In coronal section, the two leaves are usually fused or contiguous in adults. If they remain separated, then the closed space between them anteriorly is known as a cavum septum pellucidum, and posteriorly to the fornix as a cavum vergae. Such cava will communicate with the ventricular system only when their leaves are ruptured or fenestrated and it is therefore inappropriate to use the term "fifth" and "sixth" ventricles for these structures. In addition, the cava have a different embryonic development from the ventricular system and are not lined by ependymal cells. The role of the septum is not completely established, but it may take part in limbic functions such as arousal and rage mechanisms. In lower animals, the septum serves as an intermediate station for olfactory impulses. $^{20}$

\section{INCIDENCE OF CAVUM SEPTI PELLUCIDI}

The two leaves of the septum are separated in utero up to the 36 week stage of gestation. ${ }^{21} 22$ As the fetus approaches term, the persistence of the cavum decreases, so that only about one third of term infants maintain the fetal state. ${ }^{21}$

There is no clear information on the persistence of the cavum septum pellucidum in the general population at any time after the neonatal period. ${ }^{22}{ }^{23}$ Corsellis et $a l^{24}$ reported an incidence of $3 \%$ in 500 adult brains from a psychiatric hospital population; however, Schwidde, ${ }^{20}$ in an unselected series of 1032 autopsies, found a cavum septum pellucidum in $20 \%$, and Van Wagenen and Aird ${ }^{25}$ reported an incidence of $60 \%$ in their study of 30 adults. Imaging studies (discussed below) variously report cavum septum pellucidum incidence ranging between $0.7 \%$ and $37 \%$ (table 1).

\section{NEUROPATHOLOGICAL STUDIES}

Relatively few detailed studies of neuropathological changes in ex-boxers have been performed. ${ }^{24} 26$ There have been a number of individual case reports with varying amounts of clinical and pathological information provided. ${ }^{28-31}$ In only one of these case reports was a cavum septum pellucidum noted. ${ }^{31}$ Payne studied six boxers, all of which had a cavum septum (with fenestrations noted in three). ${ }^{26} \mathrm{He}$ assumed that the septal abnormalities were a secondary consequence of the enlarging ventricles.

The largest of the studies, by Corsellis et al, ${ }^{24}$ examined 15 ex-boxers ( 12 professional) whose brains had been collected in a pathology department brain bank and their boxing and social history sought retrospectively. These boxers had fought in the period 1900-1940; eight were national or world champions in their weight division. One of the striking features was their extraordinarily high exposure to boxing. The number of bouts fought ranged from 400 to $700+$, with many also fighting in fairground boxing booths (up to 30-40 fights per day over a number of years).

In this study, Corsellis et al detailed a number of neuropathological features that have become the sine qua non of chronic traumatic encephalopathy. These included:

(1) abnormalities of the septum pellucidum;

(2) cerebellar and other scarring of the brain;
(3) substantia nigral degeneration;

(4) regional occurrence of neurofibrillary tangles (these have been subsequently shown to be ubiquinated tangles that have tau immunoreactivity ${ }^{32}$ ).

With regard to the septal abnormalities, a cavum was noted in $12 / 13$ brains (two brains having an intraventricular haemorrhage that made determination of primary septal abnormalities impossible). The maximum coronal width ranged from 1 to $8 \mathrm{~mm}$ (mean $5.2 \mathrm{~mm}$ ). In $11 / 13$ cases, the cavum showed pronounced fenestration, and in most only a "few thin tags" remained. The cavum in boxers was described as having a characteristic appearance with not only fenestration but with detachment of the fornix from the undersurface of the corpus callosum, with the two flattened forniceal bodies splaying out horizontally over the dorsal surface of the thalamus. The body of the corpus callosum was often thinned as well.

Corsellis et al also speculated on the mechanism of cavum formation. Payne ${ }^{26}$ had suggested that passive ventricular enlargement stretches the leaves of the septum apart. Mawdsley and Ferguson ${ }^{34}$ invoked the concept of repeated sudden rises in intraventricular pressure leading to rupture of the septal leaves. Corsellis et al felt that, because the dorsal attachment of the septum is relatively thin and fragile, repeated head blows strain the dorsal septal attachment because of the repeated movements of the corpus callosum on the tethered fornix. He felt that once this process has been initiated, then ventricular enlargement stretches the septum and the fenestrations enlarge.

\section{RADIOLOGICAL STUDIES}

\section{Pneumoencephalographic evidence} The presence of a cavum septum pellucidum was first noted by Spillane ${ }^{19}$ who described five retired professional boxers who developed a chronic neurological problem in later life. He described in detail the clinical and pneumoencephalographic findings in these boxers and noted incidentally the presence of a cavum septum pellucidum in two of the boxers. Interestingly all of the boxers had a high exposure, with none having less than 200 bouts. One of the boxers had also gone on to fight in fairground boxing booths, having 30-40 fights per day for several years.

This work was expanded by Mawdsley and Ferguson ${ }^{34}$ and Isherwood et al ${ }^{35}$ who analysed pneumoencephalographic changes in 16 boxers. Of the 12 boxers with evidence of cortical atrophy, eight had a cavum septum pellucidum. Unfortunately little clinical information or boxing exposure was reported which would have enabled more detailed analysis. Finke et $a l^{36}$ reported an incidence of 
cavum septum pellucidum of up to $37 \%$ from pneumoencephalographic studies.

\section{Computed tomography (CT) evidence}

Harvey and Davis ${ }^{37}$ described a young boxer with chronic traumatic encephalography having had only 100 fights (25 as a professional). CT scanning showed ventricular enlargement which was confirmed by pneumoencephalography. A cavum septum pellucidum was also noted. There have also been a number of case series of active and/or retired boxers with a variety of minor radiological findings reported. ${ }^{38-44}$ In the study by Ross et al ${ }^{39}$ of 38 ex-boxers, $70 \%$ of the CT scans were normal. There was no correlation between the number of bouts or the number of knockouts with the radiological findings. It has also been questioned whether the abnormal CT scan findings noted in the older boxers were a manifestation of the normal ageing process rather than changes caused by boxing. ${ }^{14}$

A similar finding was noted in a study of amateur boxers ${ }^{45}$ in which neuropsychological function before and after a fight showed no significant differences. CT scans were performed one week after the fight; however, the results were not discussed in the paper.

\section{"Boxers with a cavum septum pellucidum were more likely to have cerebral atrophy"}

The largest study of CT scans in boxers is that of Jordan et al, ${ }^{46}$ who reported the findings in 388 active professional boxers. CT was normal in 93\% and showed "borderline" atrophy in 6\%. Boxers with a cavum septum pellucidum (14\%) were more likely to have cerebral atrophy.

Bogdanoff $e t a l^{47}$ reported the presence of a cavum septum pellucidum as a manifestation of chronic traumatic encephalopathy; however, this study has severe methodological problems. In their study of 1914 consecutive patients, only five had been boxers. Three of these boxers had been referred for cerebral imaging for investigation of a chronic neurological condition.

A contrary finding was noted by MacPherson and Teasdale. ${ }^{48}$ In 1000 consecutive patients seen at a neurosurgical trauma centre, they identified a cavum septum pellucidum in $5.5 \%$ of subjects. They concluded that the presence of an isolated cavum septum pellucidum almost certainly represents a persistent congenital anomaly of no clinical significance, and, apart from regular observation, this finding alone should not affect a boxer's career.

\section{Magnetic resonance imaging (MRI) evidence}

One of the earliest studies using MRI in boxers was by Cabanis et al. ${ }^{49}$ They examined 12 active and 40 retired boxers (13 amateur, 39 professional). A cavum septum pellucidum was noted in two boxers only. Cerebral atrophy was noted in eight, and the mamilliary bodies and optic chiasm was described as small in 30. No correlative clinical data were presented, and, given that this was in the early days of MRI using a $0.15 \mathrm{~T}$ scanner with $9 \mathrm{~mm}$ slices, technical limitations are likely to limit any conclusions that may be drawn from their findings.

\section{"No clear relation between boxing exposure and radiological findings was noted"}

Levin et $a l^{50}$ and Jordan and Zimmerman $^{51}$ each studied nine amateur boxers and found no abnormal MRI findings. Jordan and Zimmerman ${ }^{52}$ subsequently examined 21 active boxers ( 16 professional) and one retired professional boxer. Most of both the CT and MRI studies were normal; however, the authors emphasised the superiority of MRI over CT as an imaging modality and its usefulness in delineating equivocal CT abnormalities. No clear relation between boxing exposure and radiological findings was noted.

A Swedish study comparing 22 experienced amateur boxers (mean number of bouts 54 ) with age matched soccer playing and athletic controls was performed..$^{53-55}$ No significant difference was observed between the groups. Only two boxers had a cavum septum pellucidum, as did one footballer and three track athletes.

Other prospective studies such as those by Holzgraefe et $a l^{56}$ and Butler et $a l^{45}$ did not find any specific MRI abnormalities related to boxing. Another finding reported in autopsy studies of retired boxers was superficial siderosis of the cerebellum. ${ }^{57}$ Although this should be detectable using MRI, no case reports exist in which this condition has been noted.

To date radiological imaging has been unsuccessful in finding any systematic evidence of brain injury in boxers. Early anecdotal reports have not been validated using newer technologies. Clearly there are considerable differences in MRI techniques, patient positioning, slice thickness, and magnet strength, all of which may influence the findings. ${ }^{58}$

One of the abnormalities that has been reported to be of significance in earlier neuropathological studies is a cavum septum pellucidum. The finding of this abnormality varies between $0.7 \%$ and $37 \%$ using various radiological techniques; however, this finding does not correlate with either clinical or neuropsychological deficits nor with boxing exposure (table 1 ).

Magnetic resonance spectroscopy Magnetic resonance spectroscopy has been reported in ex-boxers with parkinsonism showing reduction of $\mathrm{N}$-acetylaspartate in the lentiform nucleus and is thought to indicate neuronal loss. One of three boxers studied in this fashion has a cavum septum pellucidum. The specificity of this technique is not known at this time..$^{90}$

\section{Radionucleotide studies}

A study reported cerebral blood flow measurements in a small cohort of amateur and professional boxers. ${ }^{61}$ The professional boxers were reported to have significant reductions in cerebral blood flow over the cortex, particularly in the parietal and temporal lobes. Another study of cerebral blood flow using HMPAO SPECT was performed in 42 amateur boxers from the armed services. ${ }^{62}$ There was no correlation between SPECT abnormalities and neuropsychological test performance or number of bouts fought. The relation of cavum septi pellucidi to the putative cerebral blood flow abnormalities was not discussed in either study.

\section{CHANGES IN CAVUM SEPTUM PELLUCIDUM ON SERIAL IMAGING}

An early study examining the change in size of ventricles was performed using pneumoencephalography. ${ }^{63}$ In this study, two patients with cavum septum pellucidum were noted, and more importantly the size and structure of the cavum varied from day to day. About one third of patients undergoing pneumoencephalography were noted to have "bulges" in the septum pellucidum toward the ventricles between examinations including one patient in whom this change was noted over five minutes. This suggests that the septum, with or without a cavum septum pellucidum, is not a rigidly fixed structure and may vary between examinations.

Only one study has been published of the findings of serial CT scanning in active boxers. ${ }^{64}$ In this study, 45 professional boxers in New York State had serial CT scans with a mean duration between scans of 31 months. Six (13\%) showed evidence of "progressive brain injury", with three displaying progressive cortical atrophy (one with bilateral parieto-occipital encephalomalacia), and 
three developing a cavum septum pellucidum on the repeat scans. The progressive CT changes were associated with losing more than 10 fights. No report of changes in previously documented cavi were noted.

\section{CONCLUSIONS}

The presence of a cavum septum pellucidum is a common and usually incidental finding on neuroimaging or neuropathological studies. In limited autopsy studies of boxers with extreme boxing exposure-for example, 400-900 bouts-a number of abnormalities have been noted that form part of a constellation of the pathological changes of dementia pugilistica. One of these features is a fenestrated cavum septum pellucidum. Despite this pathological evidence, neuroimaging studies using pneumoencephalography, CT, and MRI have failed to show consistent imaging abnormalities that correlate with this clinical state. Newer imaging modalities using high field MRI, diffusion tensor imaging, and measures of cortical atrophy may hold promise in the future if applied prospectively to this population.

\section{SUMMARY}

- The actual incidence of a cavum septum pellucidum in the adult population is not known but varies between $0.7 \%$ and $60 \%$ depending on the study cited.

- The presence of an isolated cavum septum pellucidum is unlikely to be of clinical importance and should not preclude a boxer from taking part in his or her sport. There is no evidence that a cavum septum pellucidum necessarily correlates with neuropsychological or clinical abnormalities or boxing exposure.

- The cavum septum pellucidum abnormality noted in the neuropathological studies as being suggestive of dementia pugilistica is fenestrated as well as being associated with forniceal abnormalities. A cavum septum pellucidum with intact walls is not a diagnostic finding of this condition.

- Very limited published evidence suggests that a cavum septum pellucidum may vary in morphology between examinations; however, the new development or serial enlargement of a cavum septum pellucidum on neuroimaging studies suggest the early development of dementia pugilistica particularly if associated with other evidence of boxing related neurotrauma. Insufficient prospective studies have been published to confirm this finding.
- There is no compelling evidence at this time that routine MRI (or other) neuroimaging will detect early evidence of chronic damage in boxers. Prospective studies are required to answer this question using more sophisticated imaging protocols.

Br J Sports Med 2002;36:157-161

Author's affiliations

P McCrory, Centre for Sports Medicine Research \& Education and Brain Research Institute, University of Melbourne, Parkville, Victoria, Australia

Correspondence to: Dr McCrory, PO Box 93, Shoreham, Victoria 3916, Australia; pmccrory@compuserve.com

\section{REFERENCES}

1 Jordan B, ed. Medical aspects of boxing. Boca Raton, FL: CRC Press, 1993

2 Ryan A. Intracranial injuries resulting from boxing: a review (1918-1985). Clin Sports Med 1987;6:31-40

3 Martland HS. Punch drunk. JAMA 1928;19:1 103-7.

4 Critchley E. Nervous disorders in boxers. Medical Annual 1937:318-20

5 Millspaugh JA. Dementia pugilstica. US Naval Medical Bulletin 1937;35:297-303.

6 Roberts AH. Brain damage in boxers: a study of the prevalence of traumatic encephalopathy among ex-professional boxers. London: Pitman, 1969

7 Roberts GW, Allsop D, Bruton C. The occult aftermath of boxing. J Neurol Neurosurg Psychiatry 1990;53:373-8.

8 Lampert PW, Hardman JM. Morphological changes in brains of boxers. JAMA 1984;251:2676-9.

9 McCown I. Boxing injuries. Am J Surg 1959:98:509-16.

10 Jordan BD, Campbell EA. Acute injuries among professional boxers in New York: a two year survey. Physician and Sportsmedicine 1988:16:87-91.

11 Jordan B. Medical and safety reforms in boxing. J Natl Med Assoc 1988;80:407-12

12 Jordan BD. Neurologic injury in boxing. Hosp Med 1991;27:93-105.

13 Cantu RC, ed. Boxing and medicine. Champaign, IL: Human Kinetics, 1995.

14 Moseley I. The neuroimaging evidence for chronic brain damage due to boxing. Neuroradiology 2000;42:1-8.

15 Bodensteiner J, Schaefer G. Dementia pugilistic and cavum septum pellucidi: born to box? Sports Med 1997;24:361-5.

16 Mettler F, Mettler C. Historic development of knowledge relating to cranial trauma. Res Publ Assoc Res Nerv Ment Dis 1945;24: 1-47.

17 Mettler C. History of medicine. Philadelphia The Blakiston Company, 1947

18 Dandy W. Congenital cerebral cysts of cavum septi pellucidi (fifth ventricle) and cavum vergae (sixth ventricle): diagnosis and treatment. Archives of Neurology and Psychiatry 1931;25:44-66.

19 Spillane J. Five boxers. BM 1962;ii:1205-10.

20 Schwidde J. Incidence of cavum septi pellucidi and cavum vergae in 1032 human brains. AMA Archives of Neurology and Psychiatry 1952:67:625-32.

21 Mott S, Bodensteiner J, Allan W. The cavum septum pellucidum in term and preterm newborn infants. J Child Neuro 1992; 7:35-8

22 Shaw C, Alvord E. Cavum septi pellucidi et vergae: their normal and pathological states. Brain 1969;92:213-24.
23 Larroche J, Baudley J. Cavum septi lucidi, cavum vergae, cavum veli interposit: Cavities de la ligne mediane. Biol Neonate 1961;3:193-236.

24 Corsellis JA, Bruton CJ, Freeman-Browne D. The aftermath of boxing. Psychol Med 1973;3:270-303.

25 Van Wegenen W, Aird R. Dilations of the cavity of the septum pellucidum and cavum vergae: report of cases. Am J Cancer 1934;20:539-57.

26 Payne EE. Brains of boxers. Neurochirurgia 1968;11:173-89.

27 Corsellis J. Boxing and the brain. BM 1989; 1:105-9

28 Brandenberg W, Hallevorden J. Dementia pugilistica mit anatomischem Befund. Virchows Archiv fur pathologische Anatomie und Physiologie und fur klinische Medizin 1954;325:680-709.

29 Neuberger K, Sinton D, Denst J. Cerebral atrophy associated with boxing. AMA Archives of Neurology and Psychiatry 1959;81:403-8

30 Grahmann H, Ule G. Beitrag zur Kenntnis der chronischen cerebralen Krankheitsbilde bei Boxern. Psychiatrica et Neurologia 1957; 134:261-83.

31 Constantinedes J, Tissot R. Lesions neurofibrillaires d'Álzhiemer genealisees sans plaques senils. Archives Suisse de Neurologie, Neurochirurgie et de Psychiatrie 1967; 100:117-30.

32 Dale GE, Leigh PN, Luthert $P$, et al Neurofibrillary tangles in dementia pugilistica are ubiquitinated. J Neurol Neurosurg Psychiatry 1991;54:116-18.

33 Tokuda T, Ikeda S, Yanagisawa N, et al. Re-examination of ex-boxers' brains using immunohistochemistry with antibodies to amyloid beta-protein and tau protein. Acta Neuropathol (Berl) 1991;82:280-5.

34 Mawdsley C, Ferguson FR. Neurological disease in boxers. Lancet 1963;ii:795-801.

35 Isherwood I, Mawdsley C, Ferguson F. Pneumoencephalographic changes in boxers. Acta Radiol 1966;5:654-61.

36 Finke J, Koch G. Das cavi septi pellucidi. Deutsch Z Nervenheilkld 1968;193:154-7.

37 Harvey PK, Davis JN. Traumatic encephalopathy in a young boxer. Lancet 1974;ii:928-9.

38 McLatchie G, Brooks N, Galbraith S, et al. Clinical neurological examination, neuropsychology, electroencephalography and computed tomographic head scanning in active amateur boxers. J Neurol Neurosurg Psychiatry 1987;50:96-9

39 Ross RJ, Casson IR, Seigal O, et al. Boxing injuries: neurologic, radiologic and neuropsychologic evaluation. Clin Sports Med 1987;6:41-51.

40 Ross RJ, Cole M, Thompson JS, et al. Computed tomography, EEG and neurologic examination in boxers. JAMA 1983;249:211-13.

41 Sironi VA, Scotti G, Ravagnati L, et al. CT scan and EEG findings in professional pugilists: early detection of cerebral atrophy in young boxers. J Neurol Sci 1982;26:165-8.

42 Kaste M, Kuurne T, Vilkki J, et al. Is chronic brain damage in boxing a hazard of the past? Lancet 1982;2:1 186-8.

43 Casson I, Sham R, Campbell E, et al. Neurological and CT evaluation of knocked out boxers. J Neurol Neurosurg Psychiatry 1982;45:170-4

44 Casson I, Siegel O, Sham R, et al. Brain damage in modern boxers. JAMA 1984;251:2663-7.

45 Butler RJ, Forsythe WI, Beverley DW, et al. A prospective controlled investigation of the cognitive effects of boxing. J Neurol Neurosurg Psychiatry 1993;56:1055-61

46 Jordan B, Jahre C, Hauser W. CT of 338 active professional boxers. Radiology 1992; 185:509-12.

47 Bogdanoff B, Natter $\mathrm{H}$. Incidence of cavum septum pellucidum in adults: a sign of boxers encephalopathy. Neurology 1989;39:991-2

48 MacPherson $\mathbf{P}$, Teasdale E. CT demonstration of a 5 th ventricle: a finding to $\mathrm{KO}$ boxers? Neuroradiology 1988;30:506-10. 
49 Cabanis EA, Perez G, Tamraz JC. Cephalic magnetic resonance imaging of boxers. Acta Radiol 1986;369(suppl):365-6.

50 Levin HS, Lippold SC, Goldman A, et al. Neurobehavioural functioning and magnetic resonance imaging in young boxers. J Neurosurg 1987:67:657-67.

51 Jordan BD, Zimmerman RD. Magnetic resonance imaging in amateur boxers. Arch Neurol 1988;45:1207-8.

52 Jordan BD, Zimmerman RD. Computed tomography and magnetic resonance imaging comparisons in boxers [see comments]. JAMA 1990;263: 1670-4.

53 Haglund Y, Persson HE. Does Swedish amateur boxing lead to chronic brain damage? 3. A retrospective clinical neurophysiological study. Acta Neurol Scand 1990;82:353-60.
54 Haglund $Y$, Bergstrand G. Does Swedish amateur boxing lead to chronic brain damage? 2. A retrospective study with $\mathrm{CT}$ and MRI. Acta Neurol Scand 1990;82:297-302.

55 Haglund Y, Eriksson E. Does amateur boxing lead to chronic brain damage? Am J Sports Med 1993;21:97-109.

56 Holzgraefe $M$, Lemme W, Funke W, et al. The significance of diagnostic imaging in acute and chronic brain damage in boxing. Int J Sports Med 1992;13:616-21.

57 Adams JH, Mitchell DE, Graham DI, et al. Diffuse brain damage of the immediate type. Brain 1977;100:489-502.

$58 \mathrm{Kemp}$ P. A critique of published studies into the effects of amateur boxing. J R Nav Med Serv 1995:81:183-9.

59 Davie C, Pirtosek Z, Barker G, et al. Magnetic resonance spectroscopic study of parkonism related to boxing. I Neurol Neurosurg Psychiatry 1995;58:688-91.

60 Ray Chaudhuri K, Lemmens G, Williams S, et al. Magnetic resonance spectroscopic study of parkinsonism related to boxing [Letter]. J Neurol Neurosurg Psychiatry 1995:59:561.

61 Rodriguez G, Ferrillo F, Montamo V, et al. Regional cerebral blood flow in boxers [Letter]. Lancet 1983:1:858.

62 Kemp PM. Houston AS, Macleod MA Cerebral perfusion and psychometric testing in boxers and controls. Eur J Nucl Med 1994;21 (suppl):S33

63 Moseley I, Sondheimer F. The 24 hour pneumoencephalogram: with particula reference to ventricular size. A series of 150 patients and a review of the literature. Clin Radiol 1975;26:389-405.

64 Zimmerman RD, Jordan BD. Neuroradiology of boxing injuries. In: Jordan BD, ed. Medical aspects of boxing. Boca Raton, FL: CRC Publishing, 1993:188-96.

\section{Call for peer reviewers}

Clinical Evidence is a regularly updated evidence based journal available world wide both as a paper version and on the internet. Clinical Evidence urgently needs to recruit a number of new contributors. Contributors are health care professionals or epidemiologists with experience in evidence based medicine and the ability to write in a concise and structured way.

Clinical Evidence needs to recruit a number of new peer reviewers. Peer reviewers are health care professionals or epidemiologists with experience in evidence based medicine. As a peer reviewer you would be asked for your views on the clinical relevance, validity and accessibility of specific topics within the journal, and their usefulness to the intended audience (international generalists and health care professionals, possibly with limited statistical knowledge). Topics are usually 2000-3000 words in length and we would ask you to review between 2-5 topics per year. The peer review process takes place throughout the year, and our turnaround time for each review is ideally 10-14 days.

If you are interested in becoming a peer reviewer for Clinical Evidence, please complete the peer review questionnaire at www.clinicalevidence.com or contact Polly Brown (pbrown@bmigroup.com). 


\section{Expression of concern about content of which Dr Paul McCrory is a single author}

This paper is authored by Dr Paul McCrory. During 2021 and 2022 there was an investigation by BJSM and BMJ which found that some of his work was the product of publication misconduct. Such misconduct includes plagiarism, duplicate publication, misquotation and misrepresentation in publications in respect of which he was listed as the sole author. ${ }^{1}$ We are placing a notice to readers on all content in relation to which he is identified as the sole author to alert them to the conclusions of our investigation.

(C) Author(s) (or their employer(s)) 2022. No commercial re-use. See rights and permissions. Published by BMJ.

Br J Sports Med 2022;0:1. doi:10.1136/bjsports-2022-106408eoc

D) Check for updates

\section{REFERENCE}

1 Macdonald H, Ragavooloo S, Abbasi K. Update into the investigation of former BJSM editor-in-chief Paul McCrory. Br I Sports Med 2022. 